\title{
SMA HYBRID COMPOSITES FOR DYNAMIC RESPONSE ABATEMENT APPLICATIONS
}

\author{
Travis L. Turner \\ Structural Acoustics Branch, MS 463 \\ NASA Langley Research Center \\ Hampton, VA 23681-2199
}

\begin{abstract}
A recently developed constitutive model and a finite element formulation for predicting the thermomechanical response of SMA hybrid composite (SMAHC) structures is briefly described. Attention is focused on constrained recovery behavior in this study, but the constitutive formulation is also capable of modeling restrained or free recovery. Numerical results are shown for glass/epoxy panel specimens with embedded Nitinol actuators subjected to thermal and acoustic loads. Control of thermal buckling, random response, sonic fatigue, and transmission loss are demonstrated and compared to conventional approaches including addition of conventional composite layers and a constrained layer damping treatment. Embedded SMA actuators are shown to be significantly more effective in dynamic response abatement applications than the conventional approaches and are attractive for combination with other passive and/or active approaches.
\end{abstract}

\section{INTRODUCTION}

Excitation levels for many aerospace vehicle structures are high due to engine noise and turbulent boundary layer fluctuating pressures. The ever-increasing need for weight-efficient structures leads to significant sonic fatigue and interior noise issues. Conventional aerospace structures typically employ passive treatments such as structural stiffening, constrained layer damping, and acoustic absorption materials to reduce the structural response and interior acoustic levels. These treatments typically suffer from substantial weight penalty and are often limited to relatively low temperatures and/or high frequencies. Smart materials may enable new structural design paradigms for high performance structures. There are many smart materials concepts, but some involving shape memory alloys (SMAs) appear to have significant advantages for applications involving adaptive stiffening and structural shape control.

Shape memory alloys are a class of smart materials that exhibit a martensitic phase transformation when cooled through the transformation temperature range $M_{s} \rightarrow M_{f}$ from the austenitic state, see figure 1. The shape memory effect (SME) can be described in simple terms in the following manner. A SMA can be easily deformed in the low temperature martensitic condition and can be returned to its original configuration by heating through the reverse transformation temperature range $A_{s} \rightarrow A_{f}$. This type of SME is termed free recovery. Conversely, in a constrained recovery configuration the SMA element is prevented from recovering the initial strain and a large tensile stress (recovery stress) is induced. A situation in which the specimen performs work (deforms under load) is called restrained recovery. Extensive work has been done to characterize these materials, both qualitatively through theoretical models [1-4] and quantitatively for particular alloys $[5,6]$. Compilations of papers have also been published, most recently

Proceedings of the 7th International Conference on Recent Advances in Structural Dynamics, The Institute of Sound and Vibration Research, University of Southampton, England, 24-27 July 2000. 
by Otsuka and Wayman [7]. Birman [8] gave a review of work done in the areas of alloy characterization, constitutive modeling, and applications.

Although there are several alloy systems that exhibit the SME, Nitinol has the most engineering significance. The recovery stress (constrained recovery) for Nitinol is a function of initial strain (prestrain) and temperature, see figure 2 [5]. The yield strength of the austenitic phase is about ten times that of the corresponding martensitic phase. The austenitic Young's modulus is also three to four times that of the martensite, see figure 3 [5].

Shape memory alloys have been investigated for a variety of applications since their discovery [9-12]. The concept of embedding SMA actuators in a composite laminate, termed a shape memory alloy hybrid composite (SMAHC), was introduced by Rogers and Robertshaw [13]. Subsequent studies have considered SMA actuators, external to the structure, for active vibration control [14-16] and shape control [17] of cantilevered beams. Other studies have proposed SMA actuators for vibration control of space structures [18] and presented analytical formulations to demonstrate the vibration/structural acoustic control of SMAHC panels [19,20]. Studies of thermal post-buckling [21] and random dynamic response [22] suppression of SMAHC panels were presented using a thermoelastic FE formulation. A different approach was offered by Ro and Baz [23-25], where thermal, static, and dynamic analyses were developed for the case of SMA actuators passing through sleeves in composite plates. Birman [26] investigated optimal distributions of SMA actuators in sleeves to improve the buckling performance of sandwich panels under mechanical loading.

SMAHC structures incorporating prestrained actuators are of particular interest in this study because of the potential for structural control due to tensile recovery stresses that are generated (constrained recovery) when the structure is placed in its service environment. In this way, an inherently elevated temperature (e.g. many aerospace applications) can be used to control structural response without control electronics or auxiliary power. The purpose of the present work is to demonstrate the dynamic response performance of SMAHC panels in comparison to conventional response abatement approaches.

\section{FORMULATION}

\section{Constitutive Modeling}

Constitutive theories for SMAHC structures can be developed from the previously mentioned shape memory models [1-4], as was done by Boyd and Lagoudas [27] and Birman [28]. However, these models are difficult to use in practice. An alternative approach is to employ a constitutive model which makes use of experimental measurement of fundamental engineering properties. A new model of the latter type was recently developed by Turner [29]. This model casts the uniaxial thermoelastic constitutive relation for a SMA actuator, along the axis of the actuator, in terms of an effective coefficient of thermal expansion (CTE):

$$
\sigma_{1 a}=E_{a}\left[\epsilon_{1}-\int_{T_{o}}^{T} \alpha_{1 a}(\tau) d \tau\right]
$$

where $E_{a}$ is the Young's modulus of the SMA, $\epsilon_{1}$ is the mechanical strain in the 1-direction, and $\alpha_{1 a}$ is the "effective" (nonlinear) CTE. Note that this expression is

Proceedings of the 7th International Conference on Recent Advances in Structural Dynamics, The Institute of Sound and Vibration Research, University of Southampton, England, 24-27 July 2000. 
valid for constrained, restrained, or free recovery applications; only the empirical method of obtaining the thermal strain changes. A measure of the nonlinear CTE $\alpha_{1 a}(T)$ over the temperature range of concern would be appropriate for free or restrained recovery applications. For constrained recovery applications, however, one must resort to measurement of the recovery stress and modulus.

It can be shown that, for constrained recovery behavior, the nonlinear thermal strain in Equation (1) can be modeled by linear thermal expansion below the austenite start temperature and can be related to the SMA recovery stress $\sigma_{r}$ and modulus by the equation

$$
\sigma_{r}=-E_{a} \int_{T_{0}}^{T} \alpha_{1 a}(\tau) d \tau \quad \text { or } \quad \int_{T_{0}}^{T} \alpha_{1 a}(\tau) d \tau=-\frac{\sigma_{r}}{E_{a}}
$$

at temperatures above $A_{s}$. Note that in this case, the nonlinear thermoelastic nature of the SMA is still captured, albeit in a different way, because measurements of recovery stress and modulus versus temperature are inherently cumulative (integrated). Also, note that an experimental approach could be devised to measure appropriate recovery stress $\sigma_{r}$ quantities for restrained recovery applications as an alternative to direct measurement of $\alpha_{1 a}(T)$. The uniaxial SMA constitutive relation for the transverse direction has a form analogous to Equation (1). However, $\alpha_{2 a}(T)$ is not related to the recovery stress, but is still nonlinear due to the differing martensitic and austenitic properties.

\section{Governing Equations}

The governing equations for the thermomechanical response of a structure subjected to combined steady-state thermal and out-of-plane dynamic mechanical loads can be derived through the use of a variational principle. The resulting finite element system of equations can be written in the following form [29]

$$
\begin{aligned}
{\left[\begin{array}{cc}
M_{b} & 0 \\
0 & M_{m}
\end{array}\right]\left\{\begin{array}{l}
\ddot{A}_{b} \\
\ddot{A}_{m}
\end{array}\right\} } & +\left(\left[\begin{array}{cc}
K_{b} & K_{B} \\
K_{B}^{T} & K_{m}
\end{array}\right]-\left[\begin{array}{cc}
K_{\Delta T} & 0 \\
0 & 0
\end{array}\right]\right. \\
& \left.+\frac{1}{2}\left[\begin{array}{cc}
N 1_{b}+\left(N 1_{b}\right)_{B} & N 1_{b m} \\
N 1_{m b} & 0
\end{array}\right]+\frac{1}{3}\left[\begin{array}{cc}
N 2_{b} & 0 \\
0 & 0
\end{array}\right]\right)\left\{\begin{array}{c}
A_{b} \\
A_{m}
\end{array}\right\} \\
& =\left\{\begin{array}{c}
F_{b}(t) \\
0
\end{array}\right\}+\left\{\begin{array}{c}
P_{b \Delta T} \\
P_{m \Delta T}
\end{array}\right\}
\end{aligned}
$$

or in compact notation as

$$
[M]\{\ddot{A}\}+\left([K]-\left[K_{\Delta T}\right]+\frac{1}{2}[N 1]+\frac{1}{3}[N 2]\right)\{A\}=\{F(t)\}+\left\{P_{\Delta T}\right\}
$$

where $[M]$ and $[K]$ are the usual system mass and linear stiffness matrices; $\left[K_{\Delta T}\right]$ is the geometric stiffness matrix due to the thermal in-plane force vector $\left\{N_{\Delta T}\right\} ;[N 1]$ and $[N 2]$ are the first- and second-order nonlinear stiffness matrices which depend linearly and quadratically upon displacement $\{A\}$, respectively; $\{F(t)\}$ is the mechanical excitation load vector, and $\left\{P_{\Delta T}\right\}$ is the thermal force vector. The subscripts $b$ and $m$ denote bending and membrane components, respectively, and the subscript $B$ indicates that the corresponding stiffness matrix is due to the laminate bending-membrane coupling stiffness matrix $[B]$. Note that the stiffness matrices $[K],\left[K_{\Delta T}\right],[N 1],[N 2]$ and the thermal force vector $\left\{P_{\Delta T}\right\}$ are all temperature dependent.

Proceedings of the 7th International Conference on Recent Advances in Structural Dynamics, The Institute of Sound and Vibration Research, University of Southampton, England, 24-27 July 2000. 
Three types of analyses are required to study the response of structures to thermal and dynamic mechanical loads, governed by Equations (4): (1) thermal buckling analysis, (2) thermal post-buckling analysis, and (3) dynamic analysis. Details of the constitutive model, FE formulation, and solution procedures can be found in Turner [29]. A Rayeigh's integral approach was used to calculate radiated acoustic quantities and transmission loss, see Turner et al. [30].

\section{RESULTS AND DISCUSSION}

The results presented in this study are intended to demonstrate the performance of SMAHC structures in comparison to conventional treatments. The results will focus on a single SMA actuator prestrain level of 5\% because changes in SMA volume fraction have a more significant effect, the SMA volume fraction is more easily varied/controlled in fabrication, and the fatigue performance of Nitinol actuators degrades substantially at prestrain levels greater than $5 \%$. The material system considered in this work consists of a E-glass/epoxy matrix material with Nitinol actuators embedded within the laminae along the direction of the glass fibers. The following material properties were used to generate the results presented in this section.

\begin{tabular}{ll} 
Glass/Epoxy \\
\hline $\mathrm{E}_{1}$ & $53.78 \mathrm{GPa}$ \\
$\mathrm{E}_{2}$ & $17.93 \mathrm{GPa}$ \\
$\mathrm{G}_{12}$ & $8.62 \mathrm{GPa}$ \\
$\nu_{12}$ & 0.25 \\
$\rho$ & $2031.8 \mathrm{~kg} / \mathrm{m}^{3}$ \\
$\alpha_{1}$ & $5.4 \times 10^{-6} /{ }^{\circ} \mathrm{C}$ \\
$\alpha_{2}$ & $30.6 \times 10^{-6} /{ }^{\circ} \mathrm{C}$
\end{tabular}

$$
\begin{array}{ll}
\frac{2}{2} \text { Nitinol } \\
\sigma_{\mathrm{r}} & \text { from figure } 2 \\
\mathrm{E} & \text { from figure } 3 \\
\nu & 0.3 \\
\rho & 6450 \mathrm{~kg} / \mathrm{m}^{3} \\
\alpha_{1 \mathrm{a}} & 6.61 \times 10^{-6} /{ }^{\circ} \mathrm{C}, \mathrm{T}<\mathrm{A}_{\mathrm{s}} \\
& \text { from equation } 2, \mathrm{~T} \geq \mathrm{A}_{\mathrm{s}} \\
\alpha_{2 \mathrm{a}} & 6.61 \times 10^{-6} /{ }^{\circ} \mathrm{C}, \mathrm{T}<\mathrm{A}_{\mathrm{s}} \\
& 11.0 \times 10^{-6} /{ }^{\circ} \mathrm{C}, \mathrm{T}>\mathrm{A}_{\mathrm{f}} \\
& \text { interpolation, } \mathrm{A}_{\mathrm{s}} \leq \mathrm{T} \leq \mathrm{A}_{\mathrm{f}}
\end{array}
$$

Recall figure 2 characterizing the recovery stress for the Nitinol considered in this study [5]. The reverse transformation (austenitic) characteristic temperatures, under free recovery conditions, for the material represented in this plot are $A_{s} \approx 35^{\circ} \mathrm{C}\left(95^{\circ} \mathrm{F}\right)$ and $A_{f} \approx 50^{\circ} \mathrm{C}\left(120^{\circ} \mathrm{F}\right)$. Note from figure 2 that $A_{f}$ is increased by mechanical constraint and increasing prestrain, while $A_{s}$ is not significantly affected by either. Furthermore, the "knee" in the recovery stress curve becomes less distinct with increasing prestrain. These are well known phenomena and are attributable to stress increasingly inhibiting the formation of austenite and completion of the reverse transformation. These insights will be useful in later discussions.

\section{SMAHC Performance}

Consider a glass/epoxy panel with dimensions of $0.36 \mathrm{x} 0.25 \times 0.001 \mathrm{~m}(14 \times 10 \times 0.045$ in.) and (45/0/-45/90/0/90/-45/0/45) lamination. The reason for the middle $0^{\circ}$-layer will be made clear subsequently. Static and dynamic performance results for a conventional (baseline) and two SMAHC laminates with clamped boundary conditions are shown in table 1 for ambient $21^{\circ} \mathrm{C}\left(70^{\circ} \mathrm{F}\right)$ and elevated temperature $82^{\circ} \mathrm{C}\left(180^{\circ} \mathrm{F}\right)$ conditions. The

Proceedings of the 7th International Conference on Recent Advances in Structural Dynamics, The Institute of Sound and Vibration Research, University of Southampton, England, 24-27 July 2000. 
SMAHC laminates in this table have a SMA volume fraction of $22 \%$. The dynamic response is forced by normally-incident, random acoustic pressure with an overall sound pressure level (OASPL) of $120 \mathrm{~dB}($ ref $20 \mu \mathrm{Pa}$ ) and a bandwidth of 10-400 Hz. A uniform modal critical damping ratio of $1 \%$ was used in the dynamic calculations.

Some general comments about this data are as follows. The buckling and resonance behavior of the SMAHC panels relative to baseline panel at ambient temperature is attributable to differences in material properties, primarily in the 2-direction in principal material coordinates. Discussion of these differences is omitted here for brevity. Comparison of the two SMAHC panels, one with SMA in all layers and the other containing SMA in the outer $0^{\circ}$ layers and in the $90^{\circ}$ layers, indicates some small performance gain is achieved by concentrating the embedded SMA in only a few layers. This approach is attractive from a fabrication point of view, particularly for automated fabrication where it is easy to imagine replacing strategic spools of prepreg with SMA ribbon in a continuous consolidation process. The middle $0^{\circ}$-layer is necessary to separate the two $90^{\circ}$ layers containing a substantial SMA volume fraction, thereby avoiding consolidation problems during cure. The remaining results/discussions will focus on SMAHC laminates with embedded SMA concentrated in the outer $0^{\circ}$ layers and in the $90^{\circ}$ layers.

It can be seen that activation of the embedded SMA has strong effects on the critical buckling temperatures, resonance frequencies, and RMS dynamic responses. The maximum displacement response power spectral density (PSD) of the SMAHC panel is shown in comparison to that of the baseline panel in figure 4. It is clear that the embedded SMA has little effect at ambient temperature. At $82\left(180^{\circ} \mathrm{F}, \Delta T=61^{\circ} \mathrm{C}\right)$, however, substantial benefit from the SMA recovery stress is evident in shifting the fundamental frequency, shifting other modes out of bandwidth, and reducing peak responses. Thus, performance can be enhanced by shifting resonance out of the excitation bandwidth and by response reduction within the excitation bandwidth.

The data in table 1 also indicates that SMAHC panels can exhibit two critical buckling temperatures ( $\Delta T_{c r}$ for inactive and active SMA states), as was previously reported $[22,29]$. This occurs for cases in which $A_{s}$ is greater than ambient temperature. This phenomenon is exemplified in figure 5, where the normalized, maximum postbuckling deflection versus temperature increase is shown for SMAHC laminates with varying SMA volume fraction. It can be seen that a volume fraction of $4 \%$ is insufficient to eliminate thermal post-buckling, but its effect in reducing the deflection is clearly observed. As little as $13 \%$ SMA will eliminate thermal post-buckling over a small range of temperatures; higher concentrations of SMA (e.g. 22\%) can greatly extend the temperature range. This behavior can be explained as follows. Thermal expansion may induce buckling at temperatures below $A_{s}$. The SMA is activated at $A_{s}$ and the recovery stress rapidly increases with temperature, which overcomes the compressive thermal stress and reduces the thermal deflection (potentially rendering the structure flat again). At higher temperatures, the rate of increase of the recovery stress with temperature diminishes and may be surpassed by the rate of increase in matrix compressive thermal stress. Further increases in temperature will cause net-compressive stress development, eventually leading to a second incidence of thermal buckling. Note that this effect can be easily avoided in practice by selecting an alloy with slightly higher Nickel content [9], which can lower $A_{s}$ to ambient temperature or below and result in a single, hightemperature buckling event.

Proceedings of the 7th International Conference on Recent Advances in Structural Dynamics, The Institute of Sound and Vibration Research, University of Southampton, England, 24-27 July 2000. 
The thermal post-buckling observations have strong implications for the panels' dynamic response. An example is shown in figure 6, where the maximum displacement PSD of the SMAHC panel $\left(v_{a}=22 \%\right)$ is shown at ambient and two elevated temperatures. At $82^{\circ} \mathrm{C}\left(180^{\circ} \mathrm{F}, \Delta T=61^{\circ} \mathrm{C}\right)$, substantial benefit of the embedded SMA is evident, while further heating to $121^{\circ} \mathrm{C}\left(250^{\circ} \mathrm{F}, \Delta T=100^{\circ} \mathrm{C}\right)$ greatly diminishes the performance (RMS $\mathrm{W}_{\max }=0.0927 \mathrm{e}-3 \mathrm{~m}$ ) because continued thermal expansion has partially overcome the beneficial effects of the recovery stress. This particular material system, glass/epoxy matrix with $22 \%$ Nitinol volume fraction at $5 \%$ prestrain, achieves its "optimal" dynamic response at approximately $82^{\circ} \mathrm{C}\left(180^{\circ} \mathrm{F}\right)$, which corresponds to the "knee" in the recovery stress curve, see figure 2. This result also holds for analogous SMAHC panels $\left(v_{a}=22 \%\right)$ with embedded Nitinol having $3 \%$ and $4 \%$ prestrain, which exhibit "optimal" dynamic performance at their respective "knee" temperatures of $54^{\circ} \mathrm{C}\left(130^{\circ} \mathrm{F}\right)$ and $66^{\circ} \mathrm{C}\left(150^{\circ} \mathrm{F}\right)$. The optimal temperature for dynamic performance will be designated by $A_{0}$ and is governed by the same thermoelastic balance as that described in the thermal post-buckling discussion. In general, with a different material system or at higher prestrain levels (in the absence of a distinct "knee"), $A_{0}$ must be determined numerically or by comparing the slope of the recovery stress curve with that of the matrix thermal stress versus temperature.

Selection of an alloy composition and processing combination that will place $A_{o}$ near the application temperature is obviously recommended for dynamic control applications. An alternate approach to achieve similar performance would entail increasing the SMA volume fraction and/or prestrain, which will result in a less efficient and/or durable design. The above discussions imply potential for a delicate balance between avoiding thermal buckling by imposing $A_{s}$ to be less than ambient temperature and "optimizing" dynamic performance by specifying $A_{o}$ to be near the application temperature. Thermal buckling can also be avoided by boundary expansion, a common approach for aerospace structures, so $A_{s}$ can be neglected in such cases and $A_{o}$ should be used to guide efficient design.

\section{SMAHC vs. Conventional}

The performance of the SMAHC laminate will now be compared with conventional approaches including increased stiffness through additional composite layers and a constrained layer damping (CLD) treatment. The conventional approaches were analyzed at ambient temperature to simulate the conditions of boundary expansion, i.e. no thermal buckling. No attempt was made to account for changes in matrix properties with temperature. A variety of dynamic response performance characteristics are compiled in table 2 for convenience of comparison. The SMAHC panel achieves a 77\% RMS displacement response reduction, relative to the baseline 9-layer glass/epoxy panel, with a $48 \%$ mass increase. A conventional composite laminate of 13 layers (45/0/-45/90/45/0/90/0/45/90/45/0/45) exhibits a similar mass increase (44\%), but only achieves a 61\% RMS displacement reduction. A RMS displacement response of $0.0474 \mathrm{e}-3 \mathrm{~m}$ (nearly equivalent to that of the SMAHC panel) can be achieved with a 16-layer (45/0/-45/90) $)_{2 \mathrm{~s}}$ conventional laminate, but at the expense of a $78 \%$ mass increase. A typical CLD treatment was modeled as a $19.16 \mathrm{~N} / \mathrm{m}^{2}\left(0.2 \mathrm{lbf} / \mathrm{ft}^{2}\right)$ weight addition and a uniform modal critical damping ratio of $6 \%$, which are considered to be representative values. This treatment also happens to result in a mass increase (42\%) similar to that of the SMAHC, but the RMS displacement response reduction of $63 \%$ is again inferior to the SMAHC. Additional insights are more clear from comparisons of the displacement response spectra.

Proceedings of the 7th International Conference on Recent Advances in Structural Dynamics, The Institute of Sound and Vibration Research, University of Southampton, England, 24-27 July 2000. 
A comparison of the respective maximum displacement response PSDs is shown in figure 7. As anticipated, the means by which the three systems achieve dynamic response reduction is quite different. The SMAHC achieves a much more weight-efficient stiffening effect relative to that of adding layers, while the CLD treatment achieves reduction primarily by damping enhancement. The weight-efficient stiffening effect of the embedded SMA is advantageous for combination with other passive treatments, which are typically more effective at higher frequencies. SMAHCs are also attractive for combination with control approaches involving piezoelectric actuators, which typically exhibit actuation authority roll-off below $200 \mathrm{~Hz}$. Such combined active-passive approaches could achieve enormous dynamic response reductions by using the embedded SMA to shift resonance frequencies and provide peak response control by stiffness enhancement, while the active approach would provide enhanced damping at resonances still within the excitation bandwidth.

The dynamic response results have direct implication for sonic fatigue life prediction. Consider an analogous acoustic pressure loading condition with an OASPL of $150 \mathrm{~dB}$ (ref $20 \mu \mathrm{Pa}$ ). It is clear that linear dynamic response analysis is no longer valid, but its use at high response levels is still common practice in the aerospace industry for sonic fatigue design. This condition is more representative of a sonic fatigue environment and will produce more realistic life predictions, while it is understood that conservative estimates will be obtained. A representative strain-life (S-N) relationship for glass/epoxy laminates was modeled by $\epsilon=7385 e^{-6}(N)^{-0.1551}$ and the maximum RMS normal strain was taken as the failure criterion. In all cases, the maximum strain was the transverse normal strain at the mid-span of the long boundary. Under these conditions, the baseline panel has an expected life of $63.7 \mathrm{k}$ cycles. The corresponding life predictions for the SMAHC, 13-layer conventional, and CLD panels are 205M, 2.84M, and 37.8M cycles, respectively. These estimates are in direct relation with the corresponding peak displacements in figure 7. It is intuitive that measures to further attenuate the SMAHC peak response would result in excellent sonic fatigue performance. The previously mentioned active-passive system, for example, might be a particularly attractive solution.

A plot of the transmission loss (TL) versus frequency for the SMAHC panel at two temperatures is shown in comparison to the baseline panel in figure 8. The main effect of the embedded SMA in its most effective state at $82^{\circ} \mathrm{C}\left(180^{\circ} \mathrm{F}\right)$ is a vast increase in the stiffness-controlled portion of the TL. This improvement is diminished at higher temperatures (e.g. $121^{\circ} \mathrm{C}$ ) for the same reasons as stated above for the dynamic response. Although the stiffness-controlled TL for the SMAHC panel shows dramatic improvement, the TL over the $400 \mathrm{~Hz}$ bandwidth is actually diminished because the mass-law effect has been moved to higher frequencies. The TL for the SMAHC panel at $82^{\circ} \mathrm{C}\left(180^{\circ} \mathrm{F}\right)$ is shown in comparison to that for the two conventional approaches in figure 9. It can be seen that the SMAHC panel is superior over a $200 \mathrm{~Hz}$ bandwidth, but not as effective at mid-range (resonance-controlled) frequencies due to the shift in mass-law effects. Combination of the SMAHC with other passive and/or active approaches is again an attractive alternative for this frequency range. At high frequencies (mass controlled) the three approaches will produce nearly equivalent TL.

\section{CONCLUSIONS}

A recently developed thermoelastic constitutive model and a finite element formulation for predicting the thermomechanical response of shape memory alloy (SMA) hybrid

Proceedings of the 7th International Conference on Recent Advances in Structural Dynamics, The Institute of Sound and Vibration Research, University of Southampton, England, 24-27 July 2000. 
composite structures (SMAHC) have been briefly described. Constrained recovery behavior of embedded SMA actuators is the focus of this study, but the constitutive formulation is also capable of modeling restrained or free recovery behavior. The constitutive model captures the material nonlinearity of the SMA with temperature. The constitutive and finite element formulations are in a form that is amenable to implementation in a commercial finite element code.

Results are shown for SMAHC panels consisting of a glass/epoxy matrix material system with embedded Nitinol actuators having a prestrain of 5\% subjected to uniform thermal and acoustic pressure loads. Performance gains can be achieved by concentrating the SMA actuators in specific layers, which is also driven by fabrication considerations. SMAHC panels can exhibit two critical buckling temperatures for $A_{s}>T_{o}$, which can be avoided by proper alloy composition selection. SMAHC structures exhibit an "optimal" operating temperature $\left(A_{0}\right)$ for dynamic response performance. $A_{0}$ is a function of the matrix material and SMA composition, volume fraction, and prestrain level. The implied conflict between specifying $A_{s}<T_{o}$ to avoid thermal buckling and $A_{o} \approx T$ to "optimize" dynamic response can be resolved by taking the conventional approach of allowing boundary expansion to prevent buckling and using $A_{0} \approx T$ to guide structural design.

The performance of a SMAHC panel was compared to that of a baseline panel and two conventional approaches including additional conventional composite layers and a constrained layer damping (CLD) treatment. The three response abatement approaches have similar added mass relative to the baseline panel, but the SMAHC panel exhibits superior dynamic response and sonic fatigue behavior. The SMAHC panel also exhibits superior transmission loss (TL) characteristics in the low frequency, stiffness controlled region; up to $200 \mathrm{~Hz}$ in this case. The SMAHC panel is less effective for $\mathrm{TL}$ at higher frequencies due to the shift in mass-law effects. However, the weightefficient stiffening effect of the embedded SMA makes it ideal for low frequency noise transmission abatement and for combination with other passive or active approaches, which are typically more effective at higher frequencies. These combined approaches have significant implications for dynamic response/sonic fatigue also.

\section{REFERENCES}

1. Tanaka, K. and Nagaki, S.: "A Thermomechanical Description of Materials with Internal Variables in the Process of Phase Transformation," Ingenieur-Archiv, vol. 51, pp. 287-299, 1982.

2. Liang, C. and Rogers, C. A.: "One-Dimensional Thermomechanical Constitutive Relations for Shape Memory Materials," J. of Intell. Matl. Syst. and Struct., Vol. 1, April, 1990, pp. 207-235.

3. Brinson, L. C.: "One Dimensional Constitutive Behavior of Shape Memory Alloys: Thermomechanical Derivation with Non-Constant Material Functions," J. of Intell. Matl. Syst. and Struct., Vol. 4:2, pp. 229-242, 1993.

4. Boyd, J. G. and Lagoudas, D. C.: "A Thermodynamical Constitutive Model for Shape Memory Materials - Part I: The Monolithic Shape Memory Alloy", Int. J. of Plasticity, 12:805-842, 1996.

5. Cross, W. B.; Kariotis, A. H.; and Stimler, F. J.: "Nitinol Characterization Study," NASA CR-1433, 1969.

Proceedings of the 7th International Conference on Recent Advances in Structural Dynamics, The Institute of Sound and Vibration Research, University of Southampton, England, 24-27 July 2000. 
6. Jackson, C. M.; Wagner, H. J.; and Wasilewski, R. J.: "55-Nitinol The Alloy with a Memory: Its Physical Metallurgy, Properties, and Applications," NASA SP-5110, 1972.

7. Otsuka, K. and Wayman, C. M. (Editors): Shape Memory Materials, Cambridge University Press, Cambridge, CB2 2RU, UK, 1998.

8. Birman, V.: "Review of Mechanics of Shape Memory Alloy Structures," Applied Mechanics Reviews, 50(11):629-645, 1997.

9. Buehler, W. J. and Wang, F. E.: "A Summary of Recent Research on the Nitinol Alloys and Their Potential Application in Ocean Engineering," Ocean Engineering, vol. 1, pp. 105-120, 1968.

10. Wayman, C. M. and Shimizu, K.: "The Shape Memory ("Marmem") Effect in Alloys," Metal Science Journal, vol. 6, pp. 175-183, 1972.

11. Wayman, C. M.: "Some Applications of Shape-Memory Alloys," Journal of Metals, pp. 129-137, June 1980.

12. Otsuka, K. and Shimizu, K.: "Pseudoelasticity and Shape Memory Effects in Alloys," International Metals Reviews, vol. 31, no. 3, pp. 93-114, 1986.

13. Rogers, C. A. and Robertshaw, H. H.: "Shape Memory Alloy Reinforced Composites," Engineering Science Preprints 25, Society of Engineering Science, Inc., ESP25.8027, 1988.

14. Rogers, C. A.: "Active Vibration and Structural Acoustic Control of Shape Memory Alloy Hybrid Composites: Experimental Results", J. of the Acoustical Society of America, 88(6):2803-2811, 1990.

15. Baz, A.; Imam, K.; and McCoy, J.: "Active Vibration Control of Flexible Beams Using Shape Memory Actuators", J. of Sound and Vibration, 140(3):437-456, 1990.

16. Srinivasan, A. V.; Cutts, D. G.; and Schetky, L. M.: "Thermal and Mechancical Considerations in Using Shape Memory Alloys to Control Vibrations in Flexible Structures", Metallurgical Transactions A, 22A:623-627, 1991.

17. Chaudhry, Z. and Rogers, C. A.: "Bending and Shape Control of Beams Using SMA Actuators", J. of Intell. Syst. and Struct., 2:581-602, 1991.

18. Maclean, B. J.; Patterson, G. J.; and Misra, M. A.: "Modeling of a Shape Memory Integrated Actuator for Vibration Control of Large Space Structures", J. of Intell. Mater. Syst. and Struct., 2:72-94, 1991.

19. Rogers, C. A.; Liang, C.; and Jia, J.: "Structural Modification of Simply-Supported Laminated Plates Using Embedded Shape Memory Alloy Fibers", Computers and Structures, 38(5/6):569-580, 1991.

20. Liang, C.; Rogers, C. A.; and Fuller. C. R.: "Acoustic Transmission and Radiation Analysis of Adaptive Shape Memory Alloy Reinforced Laminated Plates", Journal of Sound and Vibration, 145(1):23-41, 1991.

21. Zhong, Z. W.; Chen, R. R.; Mei, C.; and Pates, C. S.: "Buckling and Postbuckling of Shape Memory Alloy Fiber-Reinforced Composite Plates", Symposium on Buckling and Postbuckling of Composite Structures, ASME AD-Vol. 41/PVP-Vol. 293, pp.115-132, 1994.

22. Turner, T. L.; Zhong, Z. W.; and Mei, C.: "Finite Element Analysis of the Random Response Suppression of Composite Panels at Elevated Temperatures Using Shape Memory Alloy Fibers," AIAA-94-1324-CP, Proceedings of the 35th Structures, Structural Dynamics, and Materials Conference, Hilton Head, SC, April 18-21, pp. 136-146, 1994.

Proceedings of the 7th International Conference on Recent Advances in Structural Dynamics, The Institute of Sound and Vibration Research, University of Southampton, England, 24-27 July 2000. 
23. Ro, J. and Baz, A.: "Nitinol-Reinforced Plates: Part I. Thermal Characteristics", Composites Engineering, 5(1):61-75, 1995.

24. Ro, J. and Baz, A.: "Nitinol-Reinforced Plates: Part II. Static and Buckling Characteristics", Composites Engineering, 5(1):77-90, 1995.

25. Ro, J. and Baz, A.: "Nitinol-Reinforced Plates: Part III. Dynamic Characteristics", Composites Engineering, 5(1):91-106, 1995.

26. Birman, V.: "Stability of Functionally Graded Shape Memory Alloy Sandwich Panels", Smart Materials and Structures, 6:278-286, 1997.

27. Boyd, J. G. and Lagoudas, D. C.: "A Thermodynamical Constitutive Model for Shape Memory Materials - Part II: The SMA Composite Material", Int. J. of Plasticity, 12(7):843-873, 1996.

28. Birman, V.: "Micromechanics of Composites with Shape Memory Alloy Fibers in Uniform Thermal Fields", AIAA Journal, 34(9):1905-1912, 1996.

29. Turner, T. L.: "A New Thermoelastic Model for Analysis of Shape Memory Alloy Hybrid Composites", J. of Intell. Matl. Syst. and Struct., In Press.

30. Turner, T. L.; Singh, M. P.; and Mei, C.: "A Spectral Analysis Approach for Acoustic Radiation from Composite Panels," AIAA-95-1303-CP, Proceedings of the 36th Structures, Structural Dynamics, and Materials Conference, New Orleans, LA, April 10-13, pp. 1262-1271, 1995.

Table 1: Results for conventional and SMAHC panels.

\begin{tabular}{|c|c|c|c|c|c|c|}
\hline \multirow{2}{*}{$\begin{array}{c}\text { SMA Layer } \\
\text { Content }\end{array}$} & \multicolumn{3}{|c|}{$\mathrm{T}=21^{\circ} \mathrm{C}$, Inactive SMA } & \multicolumn{3}{c|}{$\mathrm{T}=82^{\circ} \mathrm{C}$, Active SMA } \\
\cline { 2 - 7 } & $\Delta \mathrm{T}_{\mathrm{cr}},{ }^{\circ} \mathrm{C}$ & $\mathrm{f}_{1}, \mathrm{~Hz}$ & $\begin{array}{c}\text { RMS } \\
\mathrm{W}_{\max }, \mathrm{m}\end{array}$ & $\Delta \mathrm{T}_{\mathrm{cr}},{ }^{\circ} \mathrm{C}$ & $\mathrm{f}_{1}, \mathrm{~Hz}$ & $\begin{array}{c}\text { RMS } \\
\mathrm{W}_{\max }, \mathrm{m}\end{array}$ \\
\hline None & 4.99 & 87.48 & $0.2062 \mathrm{e}-3$ & 4.99 & - & - \\
\hline All & 5.29 & 71.11 & $0.1899 \mathrm{e}-3$ & 113.6 & 173.5 & $0.0482 \mathrm{e}-3$ \\
\hline Outer $0^{\circ}, 90^{\circ}$ & 5.43 & 87.57 & $0.2058 \mathrm{e}-3$ & 122.1 & 226.4 & $0.0476 \mathrm{e}-3$ \\
\hline
\end{tabular}

Table 2: Results from baseline, SMAHC, and panels with conventional response abatement treatments.

\begin{tabular}{|c|c|c|c|c|c|c|}
\hline Case & $\begin{array}{c}\text { Added } \\
\text { Mass }\end{array}$ & $\begin{array}{c}\mathrm{f}_{1}, \\
\mathrm{~Hz}\end{array}$ & $\begin{array}{c}\text { RMS } \\
\mathrm{W}_{\max }, \mathrm{m}\end{array}$ & $\begin{array}{c}\mathrm{TL}, \\
\mathrm{dB}\end{array}$ & $\begin{array}{c}\text { Max RMS } \\
\mu \epsilon @ 120 \mathrm{~dB}\end{array}$ & $\begin{array}{c}\text { Life @ } \\
150 \mathrm{~dB}\end{array}$ \\
\hline Baseline & $0 \%$ & 87.48 & $0.2062 \mathrm{e}-3$ & 17.9 & 42.0 & $63.7 \mathrm{e}+3$ \\
\hline $\begin{array}{c}\text { SMAHC @ } \\
82^{\circ} \mathrm{C}\end{array}$ & $48 \%$ & 226.4 & $0.0476 \mathrm{e}-3$ & 14.3 & 12.0 & $205 \mathrm{e}+6$ \\
\hline 13-Layer & $44 \%$ & 128.3 & $0.0805 \mathrm{e}-3$ & 19.1 & 23.3 & $2.84 \mathrm{e}+6$ \\
\hline 16-Layer & $78 \%$ & 158.6 & $0.0474 \mathrm{e}-3$ & 20.2 & 16.8 & $23.4 \mathrm{e}+6$ \\
\hline Baseline-CLD & $42 \%$ & 73.4 & $0.0768 \mathrm{e}-3$ & 27.4 & 15.6 & $37.8 \mathrm{e}+6$ \\
\hline
\end{tabular}

Proceedings of the 7th International Conference on Recent Advances in Structural Dynamics, The Institute of Sound and Vibration Research, University of Southampton, England, 24-27 July 2000. 


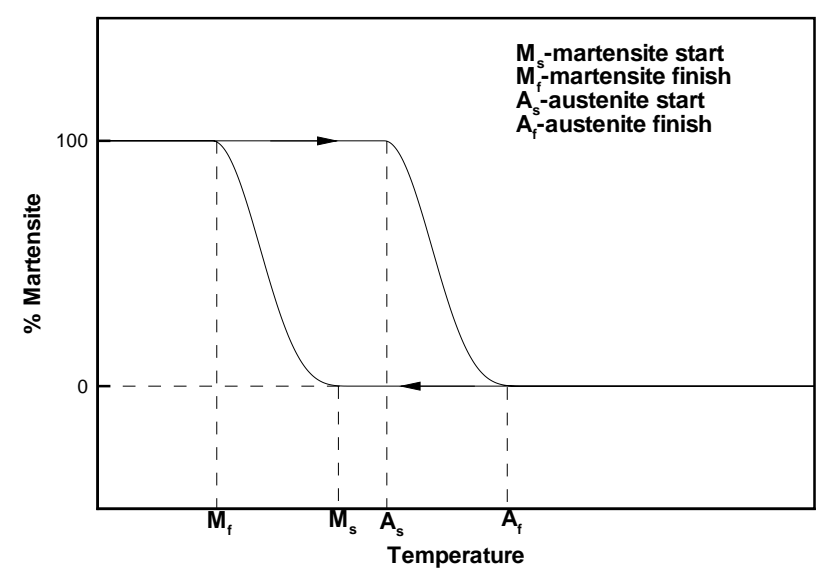

Figure 1: Martensitic and reverse transformation temperature schematic [20].

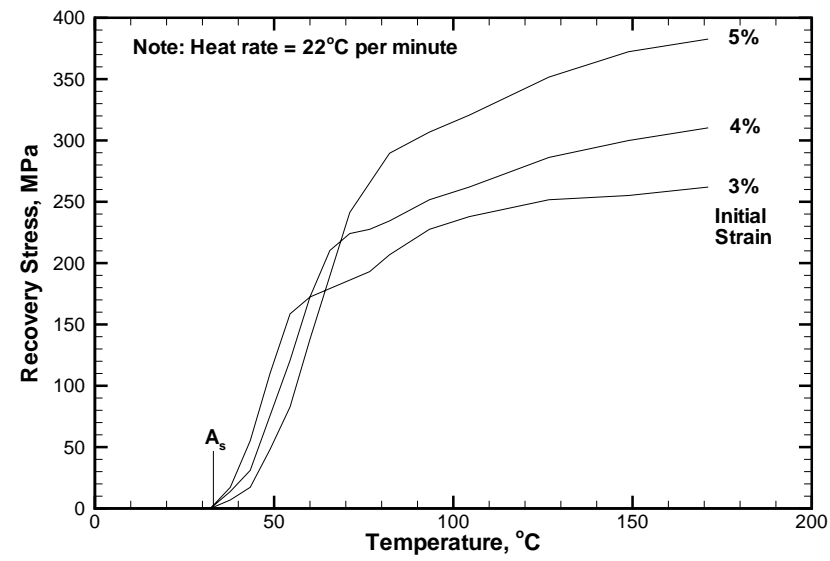

Figure 2: Nitinol recovery stress versus temperature and initial strain [5].

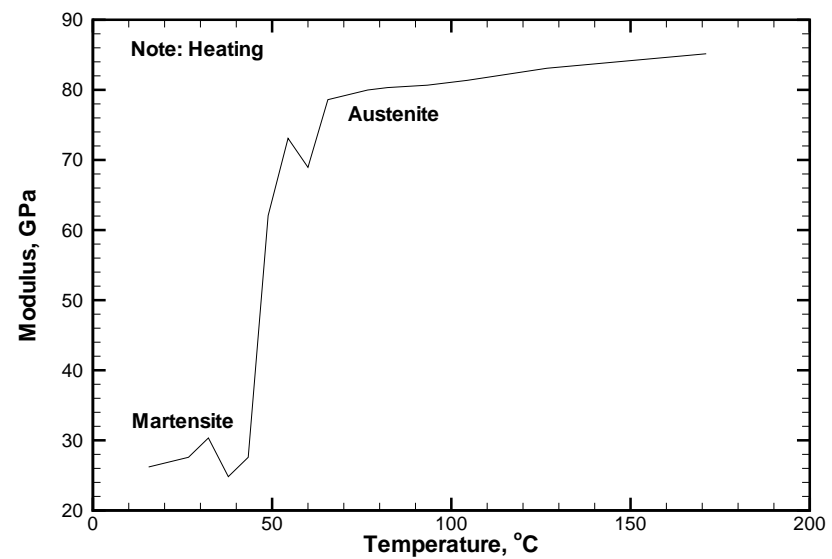

Figure 3: Nitinol Young's modulus versus temperature [5].

Proceedings of the 7th International Conference on Recent Advances in Structural Dynamics, The Institute of Sound and Vibration Research, University of Southampton, England, 24-27 July 2000. 


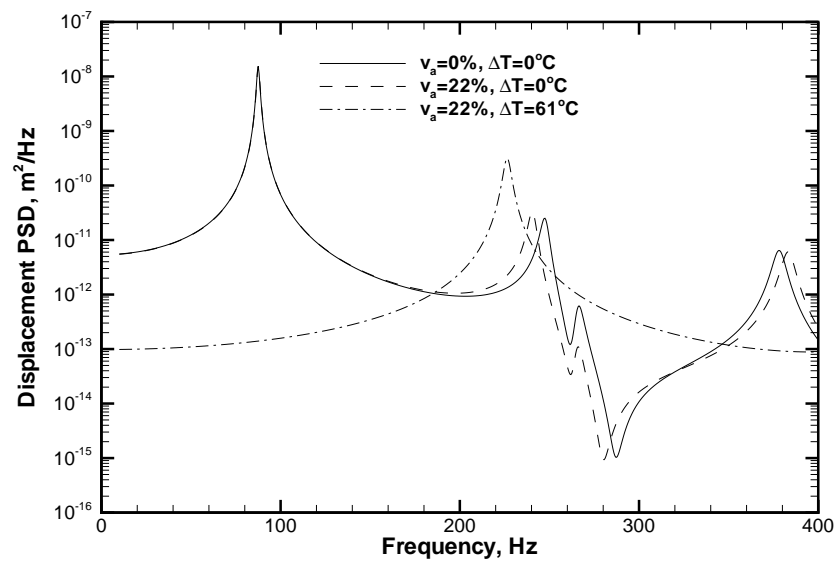

Figure 4: $W_{\max }$ PSD for the baseline and SMAHC laminates.

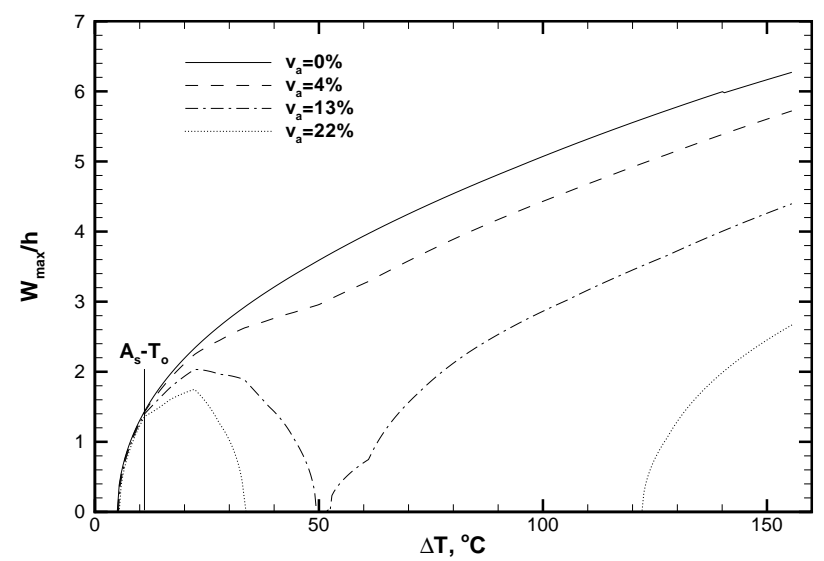

Figure 5: Post-buckling deflection of SMAHC laminates versus $\Delta T$ and $v_{a}$.

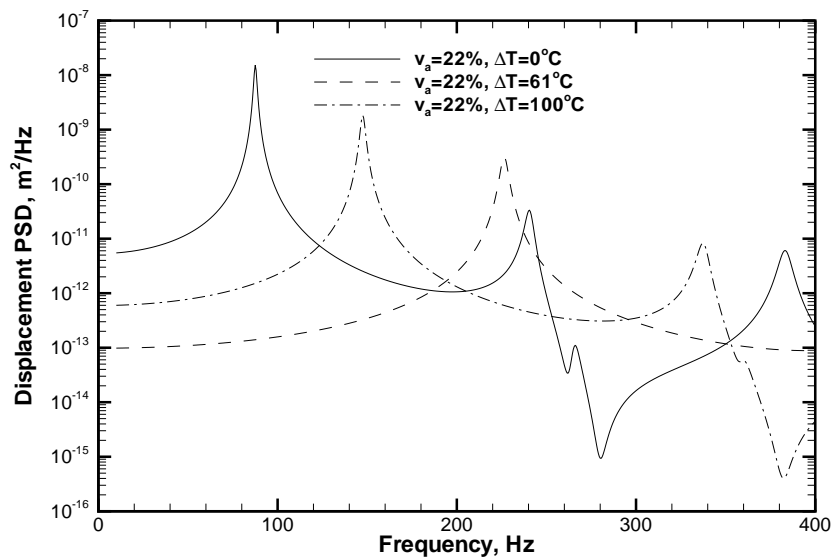

Figure 6: $W_{\max }$ PSD for a SMAHC laminate at three temperatures.

Proceedings of the 7th International Conference on Recent Advances in Structural Dynamics, The Institute of Sound and Vibration Research, University of Southampton, England, 24-27 July 2000. 


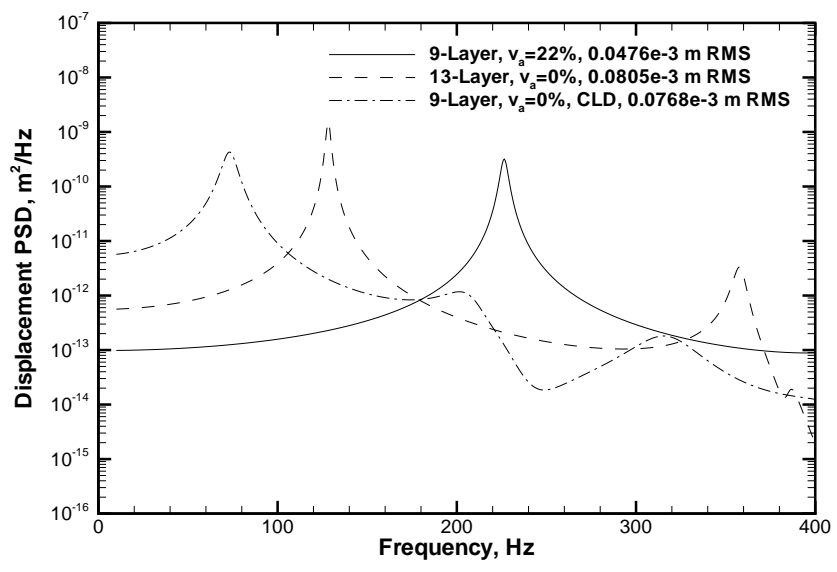

Figure 7: $W_{\max }$ PSD comparison of two SMAHCs with conventional treatments.

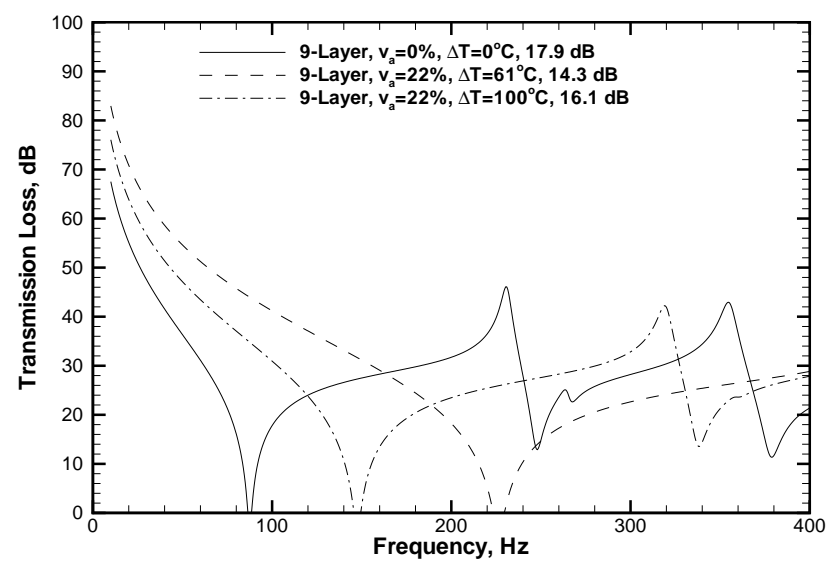

Figure 8: TL versus frequency for the baseline and SMAHC laminates.

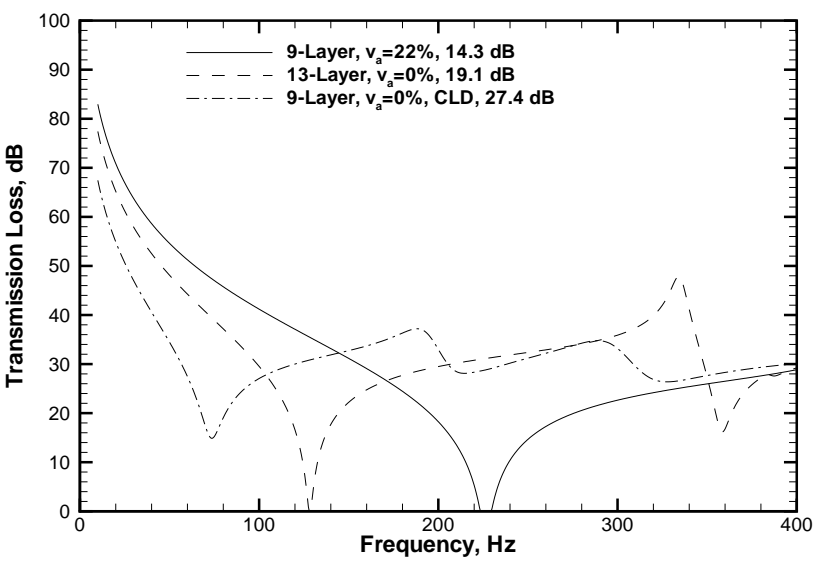

Figure 9: TL comparison of two SMAHCs with conventional treatments.

Proceedings of the 7th International Conference on Recent Advances in Structural Dynamics, The Institute of Sound and Vibration Research, University of Southampton, England, 24-27 July 2000. 